Article

\title{
Epoxy-Based Composites Embedded with High Performance BZT-0.5BCT Piezoelectric Nanoparticles Powders for Damping Vibration Absorber Application
}

\author{
Zengmei Wang ${ }^{1, *}$, Huanhuan Wang ${ }^{1}$, Wenyan Zhao ${ }^{1}$ and Hideo Kimura ${ }^{2, *}$ \\ 1 School of Materials Science and Engineering, Southeast University, Nanjing 211189, China; \\ fengxinzi.huan@hotmail.com (H.W.); 18651620827@163.com (W.Z.) \\ 2 National Institute for Materials Science, Tsukuba 305-0047, Japan \\ * Correspondence: 101011338@seu.edu.cn (Z.W.); kimura.hideo@nims.go.jp (H.K.); Tel.: +86-255-209-1085 \\ (Z.W.); +81-29-859-2437 (H.K.)
}

Academic Editor: Stevin Snellius Pramana

Received: 24 February 2017; Accepted: 6 April 2017; Published: 9 April 2017

\begin{abstract}
Lead-free, high piezoelectric performance, $\mathrm{Ba}\left(\mathrm{Zr}_{0.2} \mathrm{Ti}_{0.8}\right) \mathrm{O}_{3}-0.5\left(\mathrm{Ba}_{0.7} \mathrm{Ca}_{0.3}\right) \mathrm{TiO}_{3}(\mathrm{BZT}-0.5 \mathrm{BCT})$ sub-micron powders with perovskite structure were fabricated using the sol-gel process. A $0-3$ type composite was obtained by choosing epoxy resin as matrix and BZT-0.5BCT, acetylene black as functional phases. Particular attention was paid to the damping behavior of composite with different content of BZT-0.5BCT powders, the influence of frequency and loading force on the damping properties were also analyzed. A mathematical model was developed to characterize the damping properties of the composites. It found that the piezoelectric effects and interfacial friction play a key role in damping behavior of composites, and a large dissipated loss factor of $\tan \delta$ was found at the BZT-0.5BCT content of $20 \mathrm{vol} \%$.
\end{abstract}

Keywords: lead-free piezoelectric composites; vibration absorber; damping properties

\section{Introduction}

Unwanted vibrations may result in the fatigue and failure of structures from concrete steel buildings to precision instruments; therefore, vibration reduction and noise control is a serious engineering challenge. Much effort has been expended in attempting to minimize mechanical vibrations [1-4]. One of the approaches is to use damping materials to limit the vibration $[5,6]$. Viscoelastic material damping is recognized to make a contribution to energy loss due to hysteresis caused by internal sliding of the molecule chain. Thus, it is expected that the polymer possesses a broad, high damping peak applied to damping applications [7]. However, this is difficult or impossible for a single polymer because the height and width of the loss peak cannot be independently adjusted. Composites with piezoelectric materials contained showed excellent damping properties with wide temperature range and have attracted ever-greater attention $[8,9]$.

Piezoelectric materials such as lead zirconate titanate (PZT), lead magnesio niobate (PMN), barium titanate (BT), zinc oxide ( $\mathrm{ZnO})$, poly(vinylidene fluoride) (PVDF), etc., have been intensively investigated for great ability of converting mechanical energy into electricity [10-14]. The electric energy can be dissipated through an external resistance in piezo-damping composites [15]. Hori et al. exploited a damper material which is composed of PZT powders, conductive carbon (CB) powders and epoxy (EP) resin, and studied their damping properties and the effects of $C B$ content on the loss factor [16]. Tang et al. prepared a series of $\mathrm{BaTiO}_{3}$ filled polyurethane (PU)/ unsaturated polyester resin (UP) interpenetrating polymer networks (IPNs) and explored the relationship between 
dielectric properties and damping properties of the mixtures [17]. Malakooti et al. fabricated vertically aligned $\mathrm{ZnO}$ nanowires on nanofillers and produced hybrid carbon fiber composites. The results showed that the morphology-controlled interphase between reinforcement and matrix not only exhibited remarkable damping enhancement but also stiffness improvement [18]. Recently, a lead-free $\mathrm{Ba}\left(\mathrm{Zr}_{0.2} \mathrm{Ti}_{0.8}\right) \mathrm{O}_{3}-\mathrm{x}\left(\mathrm{Ba}_{0.7} \mathrm{Ca}_{0.3}\right) \mathrm{TiO}_{3}(\mathrm{BZT}-\mathrm{xBCT})$ piezoelectric system with optimal composition of $\mathrm{x}=0.5$ was reported to show outstanding room temperature piezoelectricity with the piezoelectric coefficient $\mathrm{d}_{33}=560-620 \mathrm{pC} / \mathrm{N}$ which is comparable to PZT [19]. Zhou, et al. developed a scalable method to synthesize perovskite type $0.5 \mathrm{Ba}\left(\mathrm{Zr}_{0.2} \mathrm{Ti}_{0.8}\right) \mathrm{O}_{3}-0.5\left(\mathrm{Ba}_{0.7} \mathrm{Ca}_{0.3}\right) \mathrm{TiO}_{3}$ (BZT-BCT) NWs with high piezoelectric coupling coefficient $(90 \mathrm{pm} / \mathrm{V})$ and the energy harvesting performance of the BZT-BCT NWs were demonstrated by fabricating a flexible nanocomposite exhibiting a high power density $(2.25 \mu \mathrm{W} / \mathrm{cm})$ [20]. Wu et al. synthesized a new kind of lead-free $0.5 \mathrm{Ba}\left(\mathrm{Zr}_{0.2} \mathrm{Ti}_{0.8}\right) \mathrm{O}_{3}-0.5\left(\mathrm{Ba}_{0.7} \mathrm{Ca}_{0.3}\right) \mathrm{TiO}_{3}$ (BZT-BCT) NWs with high piezoelectric coefficients through the electrospinning method and subsequent calcining process which could harvest weak mechanical movement energy and generated an output voltage of $3.25 \mathrm{~V}$ and output current of $55 \mathrm{nA}$ [21]. Therefore, there is much promise in such a high-performance lead-free piezoelectric material used in polymer-based damping materials through forming the composites containing piezoelectric phase and polymer matrix.

In this paper, we added BZT-0.5BCT powders and acetylene black powders into epoxy resin, and fabricated a series of piezo-damping composites through solution blending. In line with the corresponding ceramic counterpart, BZT-0.5BCT shows the highest value of $\operatorname{Pr}\left(22.15 \mathrm{mC} / \mathrm{cm}^{2}\right)$ and fairly low Ec $(68.06 \mathrm{kV} / \mathrm{cm})$ [22]. The effects of different contents of BZT-0.5BCT, frequency and loading force on damping properties were investigated. A mathematical model was established to understand the piezoelectric damping mechanism in the composites.

\section{Results and Discussions}

Figure 1 shows the XRD patterns of the three BZT-0.5BCT/acetylene black/epoxy composites. It can be observed that without addition of piezoelectric phase, Epoxy E51 shown amorphous phase, with addition of $20 \mathrm{vol} \%, 40 \mathrm{vol} \%$ and $60 \mathrm{vol} \%$ piezoelectric material. All samples show the polycrystalline perovskite phase.

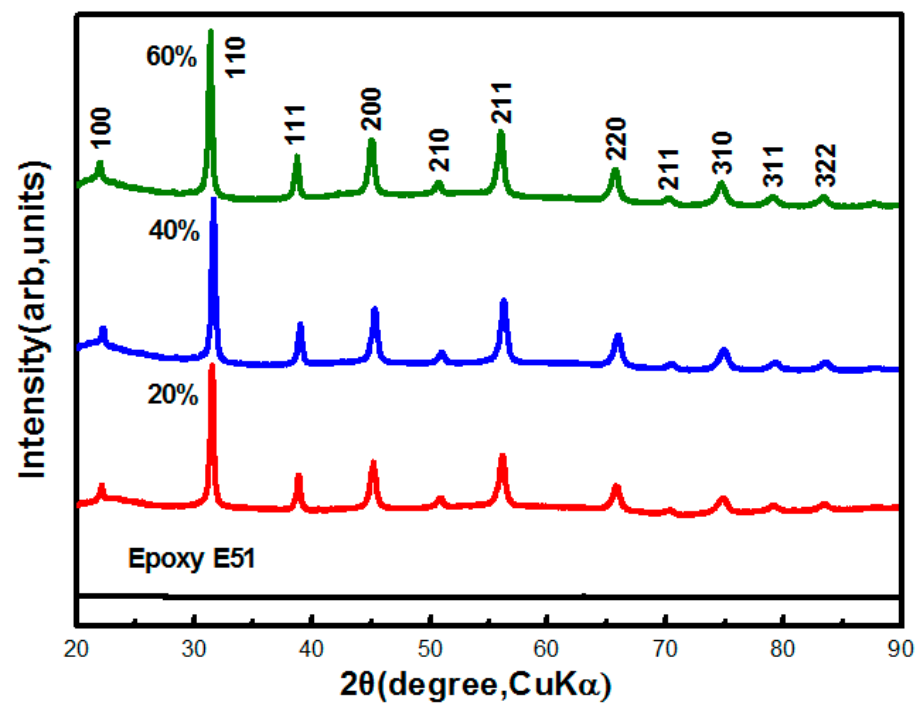

Figure 1. X-ray diffractometer (XRD) patterns of composites with different content of piezoelectric phase.

The particle distribution of the BZT-0.5BCT powder incorporated in the 0-3 epoxy-based piezoelectric composites was measured with sub-micron particle size analysis. According to the cumulative curve given in Figure 2a, the average grain size was around $500 \mathrm{~nm}$. Figure $2 \mathrm{~b}-\mathrm{d}$ present the typical SEM image of the cross-section of the composite with $20 \mathrm{vol} \%, 40 \mathrm{vol} \%$ and $60 \mathrm{vol} \%$ 
powders contained, respectively. It can be clearly observed that with the increase of piezoelectric phase, most oval BZT-0.5BCT particles and conductive acetylene black were uniformly dispersed in the matrix of Epoxy resin. A small amount of reunion, the grain size of piezoelectric phase was consistent with that in Figure 2a. However, when the volume fraction reached up to $60 \%$, the nanoparticles tended to agglomerate due to too high content of the piezoelectric phase.
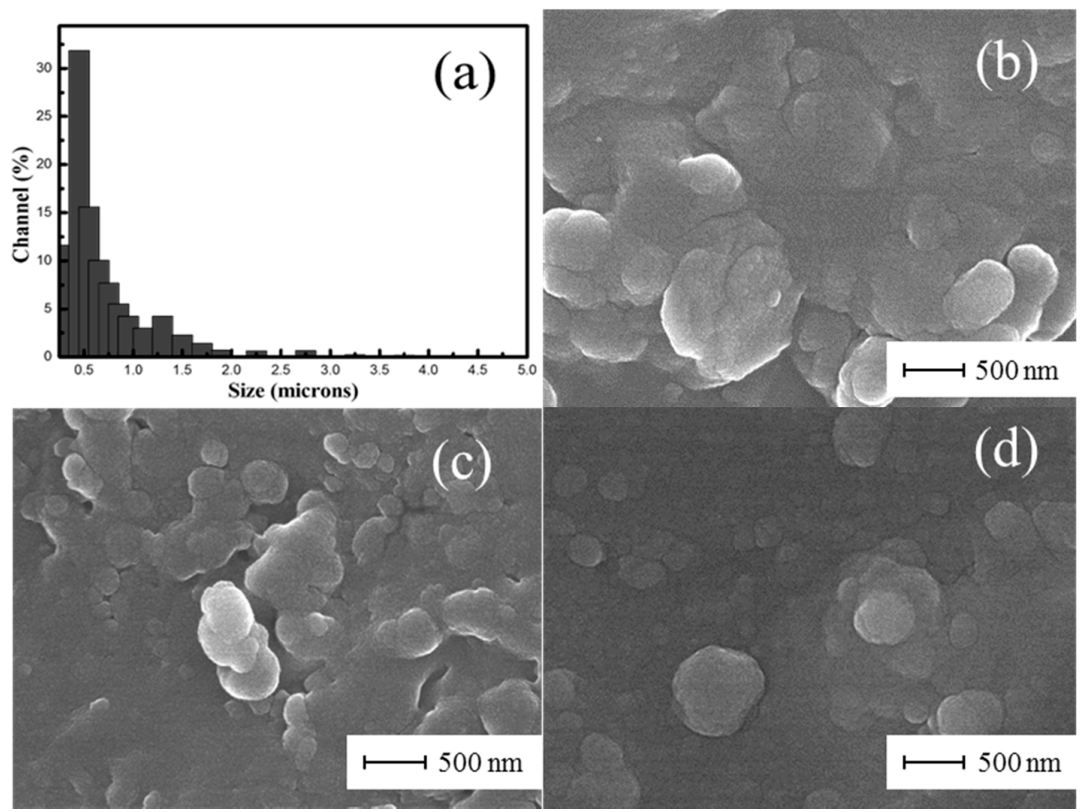

Figure 2. Typical particle size distribution histogram of $\mathrm{Ba}\left(\mathrm{Zr}_{0.2} \mathrm{Ti}_{0.8}\right) \mathrm{O}_{3}-0.5\left(\mathrm{Ba}_{0.7} \mathrm{Ca}_{0.3}\right) \mathrm{TiO}_{3}(\mathrm{BZT}-0.5 \mathrm{BCT})$ powders (a); Typical SEM image of composite with $20 \mathrm{vol} \%$ (b), $40 \mathrm{vol} \%$ (c) and $60 \mathrm{vol} \%$ (d) BZT-0.5BCT powders contained.

DMA tests generally characterize the damping properties of materials such as the storage modulus $\left(E^{\prime}\right)$ as measurement of dynamic stiffness, loss modulus ( $\left.E^{\prime \prime}\right)$ as a measurement for energy dissipation and the tangent of phase angle between the stress and strain vectors linking these two moduli (tan $\delta)$. Damping loss factor reflects an ability of converting the mechanical energy into heat energy when the material is subjected to external cyclic loading. Figure 3 shows the effect of different BZT-0.5BCT content on the loss factor of the composites when the preload fixed at $0.5 \mathrm{~N}$ and frequency $10 \mathrm{~Hz}$. In the vicinity of the glass transition temperature $(\mathrm{Tg})$ of the composites, the peaks shifted with variation of composing component.

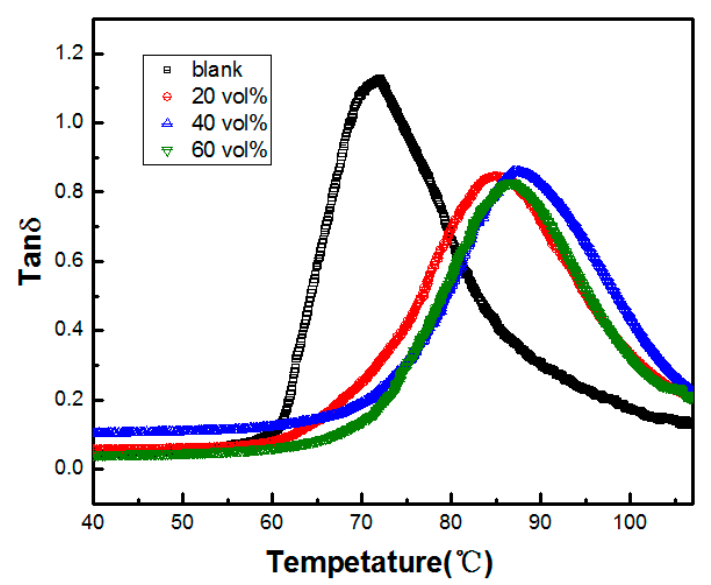

Figure 3. Loss factor-temperature curves of composite with different BZT-0.5BCT content. 
Detailed damping properties are shown in Table 1. It indicated when different volume fraction BZT-0.5BCT $(20 \%, 40 \%$ and $60 \%)$ was added to epoxy resin, the maximum loss factor and the effective temperature region initially increase and then decrease as the increase of the piezoelectric phase within our limited test range. The damping property of the composites resulted from comprehensive function of interfacial friction dissipation, retarded motion of polymer macromolecular and the piezoelectric effect. Because of the piezoelectric effect of BZT-0.5BCT powder, mechanical energy changes into electrical energy when the composites were subjected to external vibration. During the glass transition region, the composite chain movement happened under the impact load, and the piezoelectric effect of the piezoelectric phase consumed a strong response to the load which resulted in the maximum hysteresis damping and maximum lost energy. When BZT-0.5BCT powders content ranges from 20 to $40 \mathrm{vol} \%$, the interaction between the piezoelectric phase and epoxy matrix became stronger and limitation for piezoelectric powder to the polymeric segmental relaxation would enhanced. Meanwhile, $\mathrm{T}_{\mathrm{g}}$ grew from $71.8^{\circ} \mathrm{C}$ to $87.5^{\circ} \mathrm{C}$ as a result and widened the effective temperature range. However, when the volume fraction of the nanoparticles is $60 \%$, a large number of two-phase interfaces formed and the epoxy resin molecules in the vicinity of the interface layer was blocked from moving, which led to the piezoelectric effect not being able to be fully utilized and a reduction of the dissipated energy. Only when the volume fraction of BZT-0.5BCT was 0.2 can the combined effects contribute to the most powerful enhancement of damping properties. The maximum loss factor was 0.846 when the effective temperature range was maximum.

Table 1. Damping Properties of Composites with Different BZT-0.5BCT Powders Content.

\begin{tabular}{cccc}
\hline $\begin{array}{c}\text { Volume Fraction } \\
(\mathbf{v o l} \text { \%) }\end{array}$ & $\begin{array}{c}\text { Maximum Loss Factor } \\
\left(\tan \delta_{\max }\right)\end{array}$ & $\begin{array}{c}\text { Glass Transition } \\
\text { Temperature } \mathbf{T g}\left({ }^{\circ} \mathbf{C}\right)\end{array}$ & $\begin{array}{c}\text { Temperature Range } \\
(\tan \delta>\mathbf{0 . 3})\left({ }^{\circ} \mathbf{C}\right)\end{array}$ \\
\hline 0 & 1.135 & 71.8 & $62.6 \sim 90.1(27.5)$ \\
20 & 0.846 & 84.9 & $71.7 \sim 101.3(29.6)$ \\
40 & 0.857 & 87.5 & $74.8 \sim 103.9(29.1)$ \\
60 & 0.826 & 86.7 & $75.1 \sim 100.7(25.6)$ \\
\hline
\end{tabular}

Figure 4 and Table 2 show the damping properties of composite with $40 \mathrm{vol} \%$ BZT-0.5BCT powders under multi-frequency $(1,2,4,10$ and $20 \mathrm{~Hz})$. The maximum loss factor, glass transition temperature and the effective temperature range were all improved when the frequency gets higher and there was a trend of stability. The higher frequency speeded up the molecular chain movement and enhanced the piezoelectric activity of the BZT-0.5BCT powders, thus causing the improvement in the damping properties and the right shift of the peaks in the $\tan \delta$ curves.

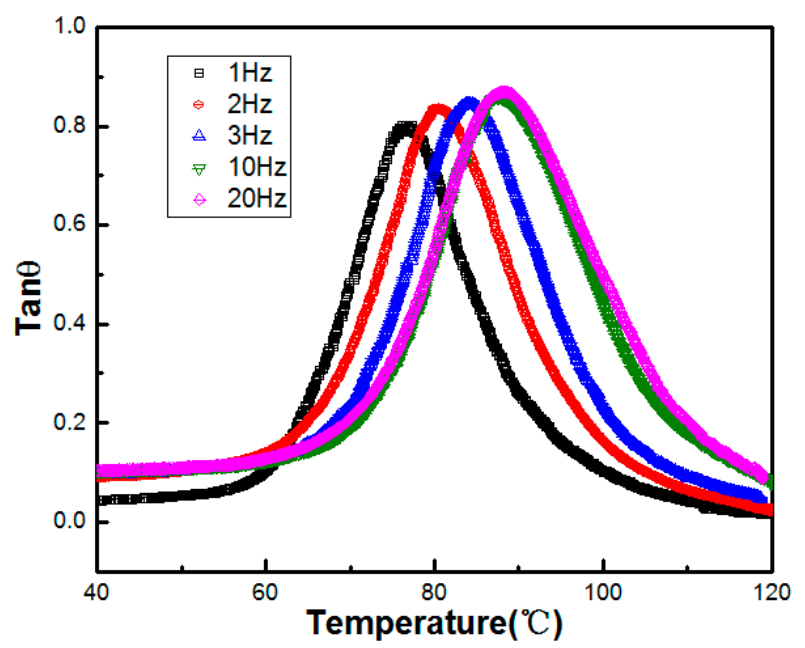

Figure 4. Loss factor-temperature curves of composites at multi-frequency. 
Table 2. Damping Properties of Composite at Different Frequency.

\begin{tabular}{cccc}
\hline $\begin{array}{c}\text { Frequency } \\
(\mathbf{H z})\end{array}$ & $\begin{array}{c}\text { Maximum Loss } \\
\text { Factor }\left(\tan \delta_{\max }\right)\end{array}$ & $\begin{array}{c}\text { Glass Transition } \\
\text { Temperature } \mathbf{T g}\left({ }^{\circ} \mathbf{C}\right)\end{array}$ & $\begin{array}{c}\text { temperature Range } \\
(\tan \delta>0.3)\left({ }^{\circ} \mathbf{C}\right)\end{array}$ \\
\hline 1 & 0.803 & 76.6 & $66.3 \sim 88.5(22.2)$ \\
2 & 0.835 & 80.3 & $68.8 \sim 94.2(25.4)$ \\
4 & 0.848 & 84.0 & $71.9 \sim 97.7(25.8)$ \\
10 & 0.858 & 87.4 & $74.8 \sim 103.8(29.0)$ \\
20 & 0.869 & 88.2 & $74.1 \sim 105.7(31.6)$ \\
\hline
\end{tabular}

Figure 5 and Table 3 show the effects of loading force of composite with $20 \mathrm{vol} \%$ addition of BZT-0.5BCT powders with the loading force ranging from $0.5 \mathrm{~N}$ to $4 \mathrm{~N}$. The maximum damping factor increased when the loading force was raised. Meanwhile, $\mathrm{T}_{\mathrm{g}}$ increased at first then remained more or less the same. The effective temperature range of the composite showed almost no change, and reached a peak at the loading force of $4 \mathrm{~N}$.

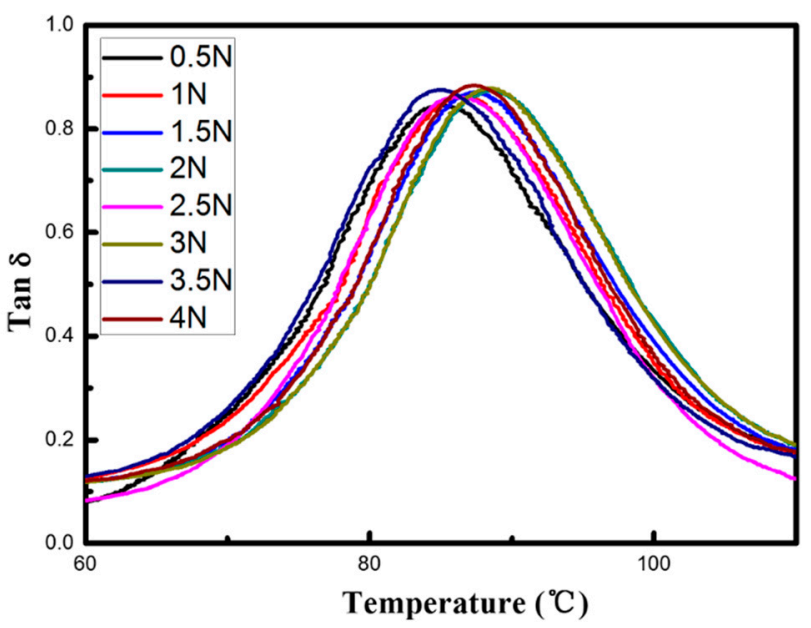

Figure 5. Loss factor-temperature curves of composites with different loading force.

Table 3. Damping Properties of Composite at Different Loading Force.

\begin{tabular}{cccc}
\hline $\begin{array}{c}\text { Loading Force } \\
(\mathbf{N})\end{array}$ & $\begin{array}{c}\text { Maximum Loss } \\
\text { Factor }(\tan \delta)\end{array}$ & $\begin{array}{c}\text { Glass Transition } \\
\text { Temperature } \mathbf{T g}\left({ }^{\circ} \mathbf{C}\right)\end{array}$ & $\begin{array}{c}\text { Temperature Range } \\
(\tan \delta>0.3)\left({ }^{\circ} \mathbf{C}\right)\end{array}$ \\
\hline 0.5 & 0.847 & 84.9 & $71.7 \sim 101.3(29.6)$ \\
1 & 0.863 & 86.4 & $72.4 \sim 101.6(29.2)$ \\
1.5 & 0.871 & 87.3 & $74.1 \sim 102.9(28.8)$ \\
2 & 0.874 & 88.6 & $75.1 \sim 103.7(28.6)$ \\
2.5 & 0.876 & 88.5 & $75.0 \sim 103.7(28.7)$ \\
3 & 0.879 & 88.5 & $75.0 \sim 103.7(28.7)$ \\
3.5 & 0.875 & 85.0 & $71.3 \sim 100.6(29.3)$ \\
4 & 0.884 & 87.3 & $74.3 \sim 101.9(27.6)$ \\
\hline
\end{tabular}

The composites behavior shown with different loading force is not like that of a conventional viscoelastic body [23]. When samples were with the preload force, the bond length and bond-angle of epoxy polymer's molecular chain would change as a tensioning process, which would cause an obstacle to the deformation of the composites. The deformable parts in the matrix become smaller while the preload force increases. On the other hand, when the preload force raises, the piezoelectric effect and the interface friction would enhance, causing an increase in the maximum loss factor. $T_{g}$ and effective temperature region mostly depended on the chain segment movement of epoxy so the peaks in $\tan \delta$ curves shift slightly to the right side. We can speculate that the piezoelectric effect and interfacial 
friction mainly contribute to composites' damping properties when the piezoelectric ceramic volume fraction exceeds 0.2 . The damping capacity was enhanced by piezo-damping as the piezoelectric effect enlarged in the piezoelectric ceramic when the loading force increased. However, the changing range was lower.

To understand the damping mechanism in the piezoelectric/polymer composites, we can analyze the components and electric circuit in the piezoelectric composite. The damping function of the piezoelectric composite mainly originates from three parts: the viscoelastic damping of the epoxy resin, the interface friction damping between the matrix and the fillers, and piezoelectric damping of BZT-0.5BCT powders. As for the piezoelectric damping, the ceramic powders first generate electric energy upon deformation and then dissipate them as thermal energy through the conductive matrix. For the piezoelectric/polymer composites, we can assume that each piezoelectric particle was in contact with the matrix as shown in Figure 6, and could be equivalent to a RLC circuit in a parallel connection. Figure 7 shows a mathematical model of the BZT-0.5BCT/acetylene black/epoxy composite with 0-3 connectivity that is the equivalent circuit between them. Then an adjustable resistance was used to simulate the conductivity of the polymer matrix and we supposed there were $\mathrm{n}$ piezoelectric particles.

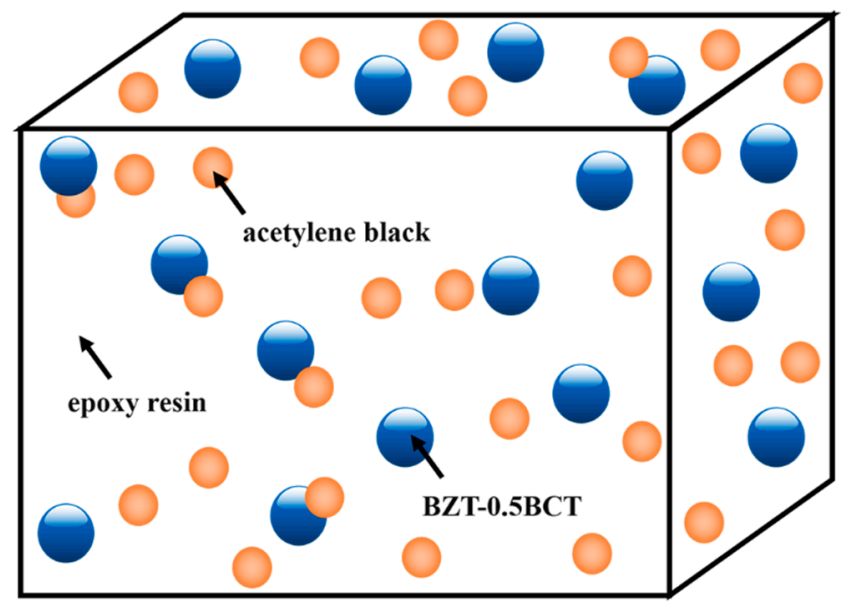

Figure 6. Schematic representation of composite.

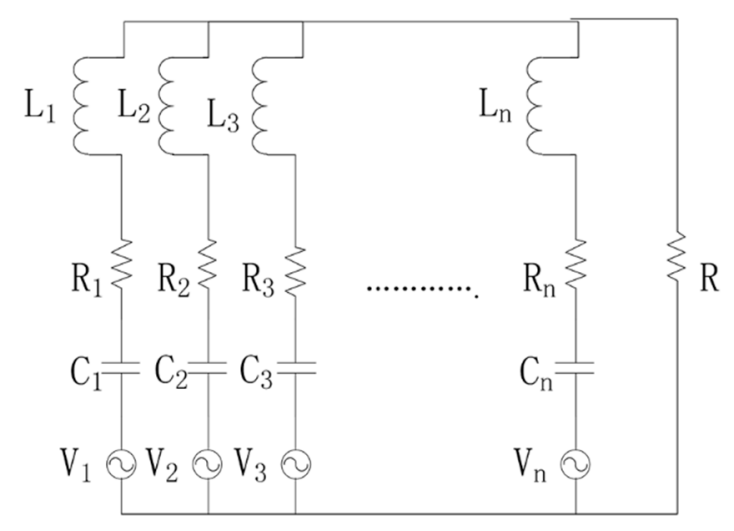

Figure 7. Equivalent circuit of composite.

When a force is applied to the composite, in a single circuit unit an alternating voltage $V_{n}$ produced by piezoelectric powder is generated and the electric energy is dissipated by the resistance $R$. The impedance $(Z)$ in the circuit cell is

$$
Z_{n}=R+\frac{1}{j \omega L_{n}+\frac{1}{j \omega C_{n}}+R_{n}}
$$


the consumption energy $\left(W_{n}\right)$ by $R$ is expressed as

$$
W_{n}=\frac{V_{n}^{2} \cdot R}{\left[R+\frac{R_{n}}{R_{n}^{2}+\left(\omega L-\frac{1}{\omega C}\right)^{2}}\right]^{2}+\left[\frac{\omega L-\frac{1}{\omega C}}{R_{n}^{2}+\left(\omega L-\frac{1}{\omega C}\right)^{2}}\right]^{2}}
$$

When it works at a resonance frequency,

$$
L=\frac{1}{\omega C}
$$

$W_{n}$ takes a maximum value in Equation (2), that is

$$
W_{n}=\frac{V_{n}^{2} \cdot R}{\left(R+\frac{1}{R_{n}}\right)^{2}}
$$

For the piezoelectric effect of piezoelectric materials, the mechanical energy transferred into electrical energy. Then it conversed into heat consumption through the conductive pathways and the load in composite materials. This indicated that the piezoelectric damping of composite was in closer association with the content of BZT-0.5BCT powders, frequency and the force, as the piezoelectric phase content directly affects the value of $\mathrm{n}$ and the loading force has an influence on the voltage $\left(V_{n}\right)$.

\section{Materials and Methods}

BZT-0.5BCT nanopowders were prepared by a sol-gel process. The starting reagents were analytical graded barium acetate $\left[\mathrm{Ba}\left(\mathrm{CH}_{3} \mathrm{COO}\right)_{2}\right]$, calcium acetate monohydrate $\left[\mathrm{Ca}\left(\mathrm{CH}_{3} \mathrm{COO}\right)_{2} \cdot \mathrm{H}_{2} \mathrm{O}\right]$, tetrabutyl titanate $\left[\mathrm{Ti}\left(\mathrm{OC}_{4} \mathrm{H}_{9}\right)_{4}\right]$, zirconium oxynitrate $\left[\mathrm{ZrO}\left(\mathrm{NO}_{3}\right) \cdot 2 \mathrm{H}_{2} \mathrm{O}\right]$, complexing agent of glacial acetic acid and solvent of 2-methoxyethanol. After obtaining sol solution, the dry gel was ground and followed post heat-treatment, then piezoelectric sub-micron powders were obtained.

The epoxy resin matrix (E-51) used in this research was provided by Wuxi Xinmeng Co. Ltd. (Wuxi, China) and acetylene black powders were provided by Taiyuan Yingze battery sales department (Taiyuan, China). To improve the surface lipophilic, BZT-0.5BCT powders were firstly treated by silane coupling agents and absolute alcohol. Conductive acetylene black was added into epoxy resin and mixed, then the pretreated piezoelectric powders and curing agents were added and stirred thoroughly under vacuum. The homogeneous viscous mixture was poured into a mold and solidified at $80^{\circ} \mathrm{C}$ for $2 \mathrm{~h}$. The BZT-0.5BCT/acetylene black/epoxy composite was obtained when cuing finished. The composite was cut, and poled. The three different composites fabricated contain $2 \mathrm{wt} \%$ acetylene black and 20, 40 and $60 \mathrm{vol} \%$ piezoelectric powders, respectively. Five $20 \mathrm{~mm} \times 3 \mathrm{~mm} \times 2 \mathrm{~mm}$ samples were fabricated for dynamic mechanical analysis.

The phase and morphology observations of composites were examined by $\mathrm{X}$-ray diffractometer (XRD, Bruker D8 Discover) with Cu-K $\alpha(1.5406 \AA)$, tube voltage $(40 \mathrm{kV})$, tube current $(100 \mathrm{~mA})$, scanning speed (0.15 degrees/s) and Field emission scanning electron microscope (FESEM, FEI Sirion-200). The damping properties of materials represented by the value of loss factor $(\tan \delta)$ were carried out using Dynamic Mechanical Analyzer (DMA, TA-Q800). The measurements were made at different frequency and loading force in the temperature range of $0 \sim 120{ }^{\circ} \mathrm{C}$ at a heating rate of $2{ }^{\circ} \mathrm{C} /$ min with multi-frequency-strain mode.

\section{Conclusions}

In this work, 0-3 BZT-0.5BCT/ acetylene black/epoxy composites with different volume fraction ratio were prepared via sol-gel process and pouring method. The microstructure and morphology of composites were studied and the damping properties of the composite with different volume fraction, frequency and loading force were mainly related. The addition of piezoelectric phase intrinsically 
broadens its effective temperature region from $27.52{ }^{\circ} \mathrm{C}$ to $29.56^{\circ} \mathrm{C}$ with only $20 \mathrm{vol} \%$ BZT-0.5BCT powders added and spurred the glass transition shift to a high temperature section. The composite damping ratio is a sum of the polymer damping and piezo-damping. The piezo effect and interfacial friction play a major role in damping capacity of the piezoelectric-damping composites when the piezo-ceramic volume fraction exceeds 0.2 . The maximum loss factor rose as the content of BZT-0.5BCT powders, frequency and loading force reached a threshold level. The composites show less sensitivity to stress due to the fact that the BZT-0.5BCT powders can retain their piezoelectric properties in comparison to polymer damping materials. Also, an equivalent circuit was established to understand the mechanism of the piezoelectric damping properties.

Acknowledgments: This work is financially sponsored by Natural Science Foundation of China (Grants No. 51002029). Part of this work was supported by the GRENE (Green Network of Excellence) project by Ministry of Education, Culture, Sports, Science and Technology-Japan.

Author Contributions: Zengmei Wang and HuanHuan Wang conceived and designed the experiments; Huanhuan Wang performed the experiments; Wenyan Zhao and Hideo Kimura analyzed the data; Wenyan Zhao revised the paper.

Conflicts of Interest: The founding sponsors had no role in the design of the study; in the collection, analyses, or interpretation of data; in the writing of the manuscript, and in the decision to publish the results.

\section{References}

1. Amick, H.; Gendreau, M. Construction vibrations and their impact on vibration-sensitive facilities. ASCE Constr. Congr. 2000. [CrossRef]

2. $\mathrm{Yu}, \mathrm{X}$.; Fu, Y. Dynamic analysis of damage behavior of vibration compaction on concrete bridges. In Proceedings of the Seventh International Conference on Traffic and Transportation Studies, Kunming, China, 3-5 August 2010.

3. Alavinasab, A.; Padewski, E.; Holley, M.; Jha, R.; Ahmadi, G. Damage Identification Based on Vibration Response of Prestressed Concrete Pipes. In Proceedings of the ASCE Pipelines Conference: Climbing New Peaks to Infrastructure Reliability—Renew, Rehab, and Reinvest, Keystone, CO, USA, 28 August-1 September 2010.

4. Fan, W.; Qiao, P. Vibration-based damage identification methods: A review and comparative study. Struct. Health Monit. 2011, 10, 83-111. [CrossRef]

5. Kwak, G.H.; Inoue, K.; Tominaga, Y.; Asai, S.; Sumita, M. Characterization of the vibrational damping loss factor and viscoelastic properties of ethylene-propylene rubbers reinforced with micro-scale fillers. J. Appl. Polym. Sci. 2001, 82, 3058-3066. [CrossRef]

6. Saravanan, C.; Ganesan, N.; Ramamurti, V. Vibration and damping analysis of multilayered fluid filled cylindrical shells with constrained viscoelastic damping using modal strain energy method. Comput. Struct. 2000, 75, 395-417. [CrossRef]

7. Skandani, A.A.; Masghouni, N.; Case, S.W.; Leo, D.J.; Al-Haik, M. Enhanced vibration damping of carbon fibers-ZnO nanorods hybrid composites. Appl. Phys. Lett. 2012, 101, 73-111.

8. Guo, X.J.; Zhang, J.S.; Xu, D.Y.; Xie, X.C.; Sha, F.; Huang, S.F. Effects of PMN Volume Fraction on the Damping Properties of 1-3 Piezoelectric Damping Composites. Appl. Mech. Mater. 2014, 624, 8-12. [CrossRef]

9. Suhr, J.; Koratkar, N.A.; Ye, D.; Lu, T.M. Damping properties of epoxy films with nanoscale fillers. J. Intell. Mater. Syst. Struct. 2006, 17, 255-260. [CrossRef]

10. Anton, S.R.; Sodano, H.A. A review of power harvesting using piezoelectric materials (2003-2006). Smart Mater. Struct. 2007, 16, R1. [CrossRef]

11. Ren, B.; Or, S.W.; Zhang, Y.; Zhang, Q.; Li, X.; Jiao, J.; Wang, W.; Liu, D.; Zhao, X.; Luo, H. Piezoelectric energy harvesting using shear mode $0.71 \mathrm{~Pb}\left(\mathrm{Mg}_{1 / 3} \mathrm{Nb}_{2 / 3}\right) \mathrm{O}_{3-0} .29 \mathrm{PbTiO}_{3}$ single crystal cantilever. Appl. Phys. Lett. 2010, 96, 083-502. [CrossRef]

12. Deng, Z.; Dai, Y.; Chen, W.; Pei, X.; Liao, J. Synthesis and characterization of bowl-like single-crystalline $\mathrm{BaTiO}_{3}$ nanoparticles. Nanoscale Res. Lett. 2010, 7, 1217-1221. [CrossRef] [PubMed]

13. Wang, X.D.; Song, J.H.; Liu, J.; Wang, Z.L. Direct-current nanogenerator driven by ultrasonic waves. Science 2007, 5821, 102-105. [CrossRef] [PubMed] 
14. Klimiec, E.; Zaraska, W.; Zaraska, K.; Gasiorski, K.P.; Sadowski, T.; Pajda, M. Piezoelectric polymer films as power converters for human powered electronics. Microelectron Reliab. 2008, 48, 897-901. [CrossRef]

15. Marra, S.P.; Ramesh, K.T.; Douglas, A.S. The mechanical properties of lead-titanate/polymer 0-3 composites. Compos. Sci. Technol. 1999, 59, 2163-2173. [CrossRef]

16. Hori, M.; Aoki, T.; Ohira, Y.; Yano, S. New type of mechanical damping composites composed of piezoelectric ceramics, carbon black and epoxy resin. Compos. Part A 2001, 32, 287-290. [CrossRef]

17. Tang, D.; Zhang, J.; Zhou, D.; Zhao, L. Influence of $\mathrm{BaTiO}_{3}$ on damping and dielectric properties of filled polyurethane/unsaturated polyester resin interpenetrating polymer networks. J. Mater. Sci. 2005, 40, 3339-3345. [CrossRef]

18. Malakooti, M.H.; Hwang, H.S.; Sodano, H.A. Morphology-Controlled ZnO Nanowire Arrays for Tailored Hybrid Composites with High Damping. ACS Appl. Mat. Interfaces 2014, 7, 332-339. [CrossRef] [PubMed]

19. Cai, Z.L.; Wang, Z.M.; Wang, H.H.; Cheng, Z.X.; Li, B.W.; Guo, X.L.; Kimura, H.; Kasahara, A. An Investigation of the Nanomechanical Properties of $0.5 \mathrm{Ba}\left(\mathrm{Ti}_{0.8} \mathrm{Zr}_{0.2}\right) \mathrm{O}_{3}-0.5\left(\mathrm{Ba}_{0.7} \mathrm{Ca}_{0.3}\right) \mathrm{TiO}_{3}$ Thin Films. J. Am. Ceram. Soc. 2015, 98, 114-118. [CrossRef]

20. Zhou, Z.; Bowland, C.C.; Malakooti, M.H.; Tang, H.X.; Sodano, H.A. Lead-free $0.5 B a\left(Z_{0.2} \operatorname{Ti}_{0.8}\right) \mathrm{O}_{3}-$ 0.5 $\left(\mathrm{Ba}_{0.7} \mathrm{Ca}_{0.3}\right) \mathrm{TiO}_{3}$ nanowires for energy harvesting. RSC Nanoscale 2016, 8, 5098-5105. [CrossRef] [PubMed]

21. Wu, W.W.; Cheng, L.; Bai, S.; Dou, W.; Xu, Q.; Wei, Z.Y.; Qin, Y. Electrospinning lead-free $0.5 \mathrm{Ba}\left(\mathrm{Zr}_{0.2} \mathrm{Ti}_{0.8}\right) \mathrm{O}_{3}-0.5\left(\mathrm{Ba}_{0.7} \mathrm{Ca}_{0.3}\right) \mathrm{TiO}_{3}$ nanowires and their application in energy harvesting. J. Mater. Chem. A 2013, 1, 7332-7338. [CrossRef]

22. Wang, Z.M.; Zhao, K.; Guo, X.L.; Sun, W.; Jiang, H.L.; Han, X.Q.; Tao, X.T.; Cheng, Z.X.; Zhao, H.Y.; Kimura, $\mathrm{H}$; et al. Crystallization, phase evolution and ferroelectric properties of sol-gel-synthesized $\mathrm{Ba}\left(\mathrm{Ti}_{0.8} \mathrm{Zr}_{0.2}\right) \mathrm{O}_{3}-\mathrm{x}\left(\mathrm{Ba}_{0.7} \mathrm{Ca}_{0.3}\right) \mathrm{TiO}_{3}$ thin films. J. Mater. Chem. C 2013, 1, 522-530. [CrossRef]

23. Guo, D.; Mao, W.; Qin, Y.; Huang, Z.; Wang, C.; Shen, Q.; Zhang, L. Damping properties of epoxy-based composite embedded with sol-gel derived $\mathrm{Pb}\left(\mathrm{Zr}_{0.53} \mathrm{Ti}_{0.47}\right) \mathrm{O}_{3}$ thin film annealed at different temperatures. J. Mater. Sci. Mater. Electron. 2012, 23, 940-944. [CrossRef]

(C) 2017 by the authors. Licensee MDPI, Basel, Switzerland. This article is an open access article distributed under the terms and conditions of the Creative Commons Attribution (CC BY) license (http:/ / creativecommons.org/licenses/by/4.0/). 